\title{
Shared Decision Making in Prostate-Specific Antigen Testing With Men Older Than 70 Years
}

\author{
Jun Li, MD, PhD, Zahava Berkowitz, MS, Thomas B. Richards, MD, \\ and Lisa C. Richardson, MD, MPH
}

Background: Little is known about how shared decision making (SDM) is being carried out between older men and their health care providers. Our study aimed to describe the use of SDM key elements and assess their associations with prostate-specific antigen (PSA) testing among older men.

Methods: We conducted descriptive and logistic regression modeling analyses using the 2005 and 2010 National Health Interview Survey data.

Results: Age-specific prevalence of PSA testing was similar in 2005 and 2010. In 2010, 44.1\% of men aged $\geq 70$ years had PSA testing. Only $27.2 \%$ (95\% confidence interval, 22.2-32.9) of them reported having discussions about both advantages and disadvantages of testing. Multiple regression analyses showed that PSA-based screening was positively associated with discussions of advantages only $(P<$ $.001)$ and with discussions of both advantages and disadvantages $(P<.001)$ compared with no discussion. Discussion of scientific uncertainties was not associated with PSA testing.

Conclusions: Efforts are needed to increase physicians' awareness of and adherence to PSA-based screening recommendations. Given that discussions of both advantages and disadvantages increased the uptake of PSA testing and discussion of scientific uncertainties has no effect, additional research about the nature, context, and extent of SDM and about patients' knowledge, values, and preferences regarding PSA-based screening is warranted. (J Am Board Fam Med 2013;26:401-408.)

Keywords: Aged, Prostate Cancer, Prostate-specific Antigen, Screening, Shared Decision Making

Since its introduction to follow men diagnosed with prostate cancer in the mid-1980s, the prostate-specific antigen (PSA) test has been used to screen men for prostate cancer, causing a downward shift in stage to disease more confined to the organ at the time of diagnosis. ${ }^{1,2}$ However, the benefit of PSA-based screening for prostate cancer on mortality is uncertain. ${ }^{3,4}$ In 2008, the US Pre-

This article was externally peer reviewed.

Submitted 24 September 2012; revised 3 December 2012; accepted 10 December 2012.

From the Division of Cancer Prevention and Control, National Center for Chronic Disease Prevention and Health Promotion, Centers for Disease Control and Prevention, Atlanta, GA.

Funding: none.

Conflict of interest: none declared.

Disclaimer: The findings and conclusions in this report are those of the authors and do not necessarily represent the official position of the Centers for Disease Control and Prevention.

Corresponding author: Jun $\mathrm{Li}, \mathrm{MD}, \mathrm{PhD}$, Division of Cancer Prevention and Control, Centers for Disease Control and Prevention, 4770 Buford Hwy., Mail Stop K-55, Atlanta, GA, 30341 (E-mail: ffa2@cdc.gov). ventive Service Task Force (USPSTF) recommended against screening for prostate cancer among men $\geq 75$ years old because the incremental benefits of treatment for screening-detected prostate cancer were negligible. ${ }^{5}$ In 2012, the USPSTF revised its recommendation for PSA-based screening, recommending against routine PSA screening among men of all ages. ${ }^{6}$ Although the American Cancer Society and the American Urological Association agree that men who have less than a 10 -year life expectancy should not be screened, they also point out that decisions need to be individualized because some men older than 70 years might live for many more years. ${ }^{7,8}$ Prior studies from 2010 and 2011 reported that PSA-based screening for prostate cancer is being performed in a substantial number of men aged 70 years and older, with rates peaking at ages 70 to 74 years. $^{9-11}$

Because of the uncertain effectiveness of PSAbased screening for reducing prostate cancer mortality and the potential harms resulting from overdiagnosis and overtreatment, most prostate cancer 
screening guidelines recommend that before testing clinicians should have a balanced discussion with patients about 3 key elements: the advantages, disadvantages, and scientific uncertainties of the benefits associated with screening. ${ }^{7,8}$ The process of making a decision based on these discussions is commonly referred to as shared decision making (SDM), which is also recommended. ${ }^{7,8}$ Studies have shown that physician's recommendations, patient's demographics, and health-related factors including age, education, estimated life expectancy, and comorbidity are associated with prostate cancer screening among older men. ${ }^{10-13}$ To our knowledge, the role of each key element in SDM in influencing PSA testing has not been well studied, in part because this information has not been collected by national surveys. ${ }^{14-16}$ In 2010, questions about these 3 key elements of SDM were added to the cancer control supplement of the National Health Interview Survey (NHIS), which is supported by the Division of Cancer Control and Prevention at the Centers for Disease Control and Prevention and the National Cancer Institute.

The purposes of this study were 3 -fold: first, to estimate the prevalence of discussions about the advantages, disadvantages, and the scientific uncertainties of PSA testing before ordering the tests; second, to determine the effect of these key elements of SDM on the uptake of PSA-based screening; and third, to assess the effect of the 2008 USPSTF prostate cancer screening recommendations on PSA-based testing in this older population.

\section{Methods}

\section{Data Source}

To estimate the prevalence of PSA testing among men $\geq 40$ years old, we used nationally representative data from the 2005 and 2010 NHIS (http:// www.cdc.gov/nchs/nhis.htm). The survey is an annual, in-person, cross-sectional household survey that monitors health trends among noninstitutionalized US civilians aged 18 years and older. The final response rates for the adult samples were $69.0 \%$ in 2005 and $60.8 \%$ in 2010. More information on NHIS has been described elsewhere. ${ }^{13}$ Data from the 2010 NHIS included 6220 men. Excluded were 298 men (4.0\%) who had a history of or missing information on prostate cancer and $808(11.0 \%)$ who had a reason other than routine screening or missing information on PSA testing.
Similarly, the 2005 NHIS analysis included 7192 men after excluding 1298 (15.2\%). The analysis of the effect of SDM elements on PSA-based screening was restricted to the 1045 men aged 70 years and older in the 2010 NHIS who reported no history of prostate cancer. The reasons to include men aged 70 to 74 years old are (1) men in this age group have the highest screening rate for prostate cancer and (2) about one fourth of men who had a low life expectancy (at least a $48 \%$ risk of 5 -year mortality as defined by Drazer et $\mathrm{al}^{10}$ ) in this age group underwent PSA screening.

\section{Study Variables}

In both the 2005 and 2010 surveys, men aged 40 years and older were asked several questions about prostate cancer and PSA testing, including whether they had ever had a PSA test and, if so, the time of their most recent test and the main reason for having the test. The primary outcome of this analysis was defined as receipt of a PSA test, which was a part of a routine examination within the 12 months preceding the survey, among men with no history of prostate cancer.

The primary factors of interest in the 2010 analysis were 3 SDM elements: whether men had discussions with their providers about the advantages, disadvantages, and experts' disagreement about the benefits of PSA-based screening for prostate cancer (noted hereafter as scientific uncertainties) before ordering the PSA tests. For the descriptive and multiple regression analyses, we combined the first 2 items (advantages and disadvantages) to form a new variable with the following 4 mutually exclusive categories: discussion of advantages only, discussion of disadvantages only, discussion of both advantages and disadvantages, or no discussion.

We grouped age into 3 categories: 70 to 74 years, 75 to 79 years, and $\geq 80$ years. Race and ethnicity were grouped into 4 mutually exclusive categories: non-Hispanic white, non-Hispanic black, Hispanic, and non-Hispanic other. We designated marital status using 3 categories: married or living with a partner, divorced/widowed/separated, and never married. We classified educational status as less than high school, high school graduate, and more than a high school diploma. We defined access to health care with the question of whether respondents had a usual source of care, excluding emergency department visits. We also included the following health-related characteristics, which might 
have an influence on prostate cancer screening: a family history of prostate cancer (whether a respondent's father, brother, or son had previously been diagnosed with prostate cancer); number of the following comorbidities (none, 1, 2, or $\geq 3$ diseases): hypertension, stroke, emphysema, diabetes, chronic bronchitis, failing kidneys, liver condition, and heart disease; and a diagnosis of cancer other than prostate cancer.

\section{Statistical Analysis}

We used SAS-callable SUDAAN 9.2 software (Research Triangle Institute, Research Triangle Park, NC) for the analyses to account for the stratified, multistage-cluster sampling design. ${ }^{17} \mathrm{We}$ estimated the age-specific prevalence and corresponding $95 \%$ confidence interval (CI) of PSA testing by age group and survey year. We also estimated the prevalence of the discussion of advantages, disadvantages, and scientific uncertainties. We then conducted bivariate analysis and multiple logistic regression to determine the unadjusted and adjusted associations between PSA testing and SDM and demographic and health-related characteristics. For the unadjusted and adjusted analyses, we used the mutually exclusive 4-level variable describing discussions with the provider.
We presented the results from the multiple regression model as adjusted percentages or predicted margins. ${ }^{18}$ Predicted margins for each subgroup were calculated from the logistic regression model as the average of the predicted probabilities of PSA test use, assuming that all survey participants were in that subgroup. These adjusted percentages allow easy comparisons among categories within a covariate. We calculated the relative standard error (standard error/estimated percentage) $\times$ 100 for each estimated percentage. An estimated percentage is considered unstable if its relative standard error is $>30 \%$ or if the sample size is $<30$; these values should be interpreted with caution. We used general linear contrasts to assess the difference between each estimate with a reference level within a variable.

\section{Results}

The overall prevalence of PSA screening of men aged 40 years and older was $26.3 \%$ in 2005 and $27.5 \%$ in 2010. As shown in Figure 1, men aged 70 to 74 years had the highest prevalence of PSA testing (49.0\%). The frequency of PSA screening in 2005 and 2010 were similar for each age group. We assessed the prevalence of PSA testing and SDM factors based on data from the 2010 NHIS. Among

Figure 1. Age-specific prevalence and $95 \%$ confidence intervals of prostate-specific antigen screening within the past year, by year (2005 and 2010) of the National Health Interview Survey.

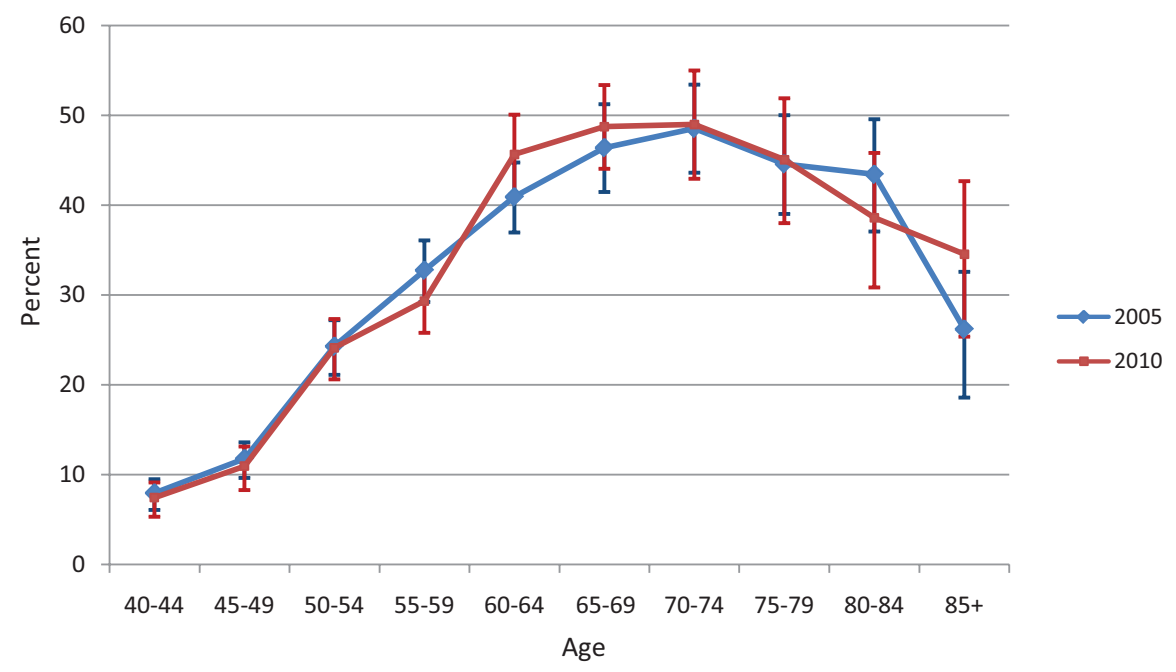

\begin{tabular}{|c|c|c|c|c|c|c|c|c|c|c|c|}
\hline Year/Age group & $40-44$ & $45-49$ & $50-54$ & $55-59$ & $60-64$ & $65-69$ & $70-74$ & $75-79$ & $80-84$ & $85+$ & Total \\
\hline $2005(n)$ & 1263 & 1235 & 1099 & 996 & 772 & 571 & 488 & 353 & 258 & 157 & 7192 \\
\hline $2010(n)$ & 999 & 976 & 952 & 861 & 777 & 610 & 396 & 304 & 203 & 142 & 6220 \\
\hline
\end{tabular}


men aged 70 years and older, 44.1\% (95\% CI, 40.5-47.8) reported having had a PSA test, $41.7 \%$ (95\% CI, 38.0-45.5) reported having a discussion about the advantages, $20.1 \%$ (95\% CI, 17.5-23.0) reported having a discussion about the disadvantages, and 15.1\% (95\% CI, 12.7-18.0) reported having a discussion about scientific uncertainties. Among men who underwent PSA testing, only 27.2\% (95\% CI. 22.2-32.9) reported having discussions about both advantages and disadvantages (data not shown).

Findings from the unadjusted analysis (Table 1) showed that all variables examined were significantly associated with PSA testing except for family history of prostate cancer and comorbidity. The percentage of PSA testing was significantly lower among men aged $\geq 80$ years $(37.0 \%$; $95 \% \mathrm{CI}$, $31.4-43.0)$ than among men aged 70 to 74 years (49\%; 95\% CI, 43.0-55.0). Discussions of advantages only and of both advantages and disadvantages were significantly more likely than no discussion to result in PSA testing.

Findings from the multiple logistic regression analysis (Table 2) revealed that after controlling for all other variables in the model, the prevalence of PSA testing was significantly higher among men who reported having had a discussion about advantages only $(57.4 \%$; 95\% CI, 48.9-65.4) or about both advantages and disadvantages $(55.9 \%$; $95 \%$ CI, 46.9-64.6) compared with men reporting no discussion (34.3\%; 95\% CI, 29.2-39.9). Significantly higher prevalence of PSA testing was observed among men aged 70 to 74 years compared with men aged $\geq 80$, among college-educated men compared with men with less than a high school education, and among married men or those living with a partner compared with men who were divorced, separated, or widowed.

\section{Discussion}

Our analysis reveals that a large proportion of men aged 70 and older are undergoing PSA-based screening for prostate cancer. More than $70 \%$ of these men reported not having discussions about advantages and disadvantages. When conversations did occur, health care providers more often focused on the advantages than disadvantages of PSA testing. Infrequent discussion of disadvantages of PSA screening had been observed by several studies. ${ }^{14,16}$ Among these, Hall et $\mathrm{al}^{14}$ administered a national survey of physicians regarding prostate cancer screenings and found that more than two thirds of physicians who provided a prescreening discussion encouraged their patients to have the test; fewer than $2 \%$ discouraged testing. Hoffman and colleagues ${ }^{16}$ surveyed 240 men aged 40 years and older and found that health care providers more frequently emphasized the advantages of screening (71\%) than the disadvantages (18\%). It has been consistently reported that a physician's advice is a major determinant in a man's decision to have a PSA test. ${ }^{19-21}$ Lack of SDM in the physicians' office may result in prostate cancer screening that could cause unnecessary physical, psychological, and financial harm to patients. Prostate cancer screening guidelines from major medical organizations such as the American Cancer Society and the American Urological Association recommend that patients be fully informed by health care providers about the advantages, disadvantages, and the scientific uncertainties associated with PSA testing and that patients' preferences should be considered in screening decisions. ${ }^{7,8}$

In 2012, on the basis of new evidence about the benefits and harms of the PSA test, the USPSTF revised its 2008 recommendations on prostate cancer screening. The new statement does not recommend routine PSA-based screening for any men, regardless of age. ${ }^{6}$ The USPSTF understands that screening decisions may differ based on patientspecific characteristics and clinical situations and emphasizes that men and their health care providers should continue to discuss the advantages and disadvantages of PSA testing for prostate cancer screening and that they should make informed decisions about whether testing is right for them. Efforts are needed to enhance physicians' knowledge of and adherence to these SDM recommendations before ordering a PSA test.

We found that discussions of both advantages and disadvantages were associated with a higher prevalence of PSA test use. Similar findings also was observed by Ross and coworkers ${ }^{22}$ in an analysis of 2000 NHIS data and by Tannor et $\mathrm{al}^{23}$ in a study of African American men. However, in both of these studies it was not clear whether physicians provided balanced information on the harms and benefits of prostate cancer testing and whether patients were fully engaged in the discussion. Besides varied levels of knowledge among health care providers about SDM and how to conduct it, mis- 
Table 1. Unadjusted Associations Between Prostate-Specific Antigen Screening and Sociodemographic and Screening-Related Factors Among Men Aged 70 Years or Older, National Health Interview Survey 2010

\begin{tabular}{|c|c|c|c|c|}
\hline & $\mathrm{N}^{*}$ & Percentage $^{\dagger}$ & 95\% Confidence Interval & $P^{\ddagger}$ \\
\hline Total & 1045 & 44.1 & $40.5-47.8$ & \\
\hline Age, years & & & & .02 \\
\hline $70-74$ & 396 & 49.0 & $43.0-55.0$ & Reference \\
\hline $75-79$ & 304 & 45.0 & $38.2-52.1$ & .400 \\
\hline$\geq 80$ & 345 & 37.0 & $31.4-43.0$ & .006 \\
\hline Race/ethnicity & & & & $<.001$ \\
\hline Non-Hispanic white & 727 & 47.0 & $42.9-51.1$ & Reference \\
\hline Non-Hispanic black & 144 & 32.7 & $24.4-42.3$ & .004 \\
\hline Non-Hispanic other & 66 & 27.4 & $16.7-41.4$ & .011 \\
\hline Hispanic & 108 & 30.1 & $20.7-41.6$ & .003 \\
\hline Education & & & & $<.001$ \\
\hline Less than high school & 306 & 32.1 & $25.5-39.4$ & Reference \\
\hline High school graduate & 308 & 40.1 & $34.2-46.3$ & .096 \\
\hline Some college & 202 & 47.3 & $39.7-54.9$ & .003 \\
\hline College graduate & 223 & 59.0 & $51.0-66.6$ & $<.001$ \\
\hline Marital status & & & & $<0.001$ \\
\hline Married or living with partner & 589 & 49.3 & $44.8-53.8$ & Reference \\
\hline Widowed, divorced, or separated & 400 & 30.2 & $25.2-35.7$ & $<.001$ \\
\hline Never married & 55 & 39.8 & $27.1-54.2$ & .206 \\
\hline Usual source of medical care & & & & $<.001$ \\
\hline Yes & 998 & 45.5 & $41.8-49.3$ & Reference \\
\hline No & 47 & 11.1 & $4.38-25.5^{\S}$ & $<.001$ \\
\hline Family history of prostate cancer & & & & .092 \\
\hline Yes & 78 & 53.7 & $42.4-64.6$ & Reference \\
\hline No & 915 & 43.4 & $39.5-47.4$ & .091 \\
\hline Comorbidity & & & & .115 \\
\hline None & 229 & 37.8 & $30.9-45.2$ & Reference \\
\hline 1 disease & 336 & 47.0 & $41.1-52.9$ & .045 \\
\hline 2 diseases & 278 & 42.4 & $35.6-49.4$ & .385 \\
\hline$\geq 3$ diseases & 202 & 48.5 & $40.4-56.6$ & .049 \\
\hline Had any cancers excluding prostate cancer? & & & & .018 \\
\hline Yes & 182 & 52.9 & $44.8-60.9$ & Reference \\
\hline No & 863 & 42.0 & $38.0-46.2$ & .018 \\
\hline Discussed scientific uncertainties & & & & $<.001$ \\
\hline Yes & 138 & 63.2 & $53.9-71.6$ & Reference \\
\hline No & 874 & 40.8 & $36.9-44.8$ & $<.001$ \\
\hline Discussed advantages/disadvantages & & & & $<.001$ \\
\hline None & 606 & 31.4 & $26.9-36.3$ & Reference \\
\hline Advantages only & 197 & 60.0 & $51.7-67.8$ & $<.001$ \\
\hline Disadvantages only" & - & - & - & - \\
\hline Both & 185 & 62.6 & $54.6-70.0$ & $<.001$ \\
\hline
\end{tabular}

*Number may differ from totals because of "don't know," refused, or missing responses.

${ }^{\dagger}$ Percentage of population estimates adjusted for National Health Interview Survey sampling design.

${ }^{\ddagger} \chi^{2}$ Test when the $P$ value is located on a row of a main effect. $P$ values for a general linear contrast comparing a row's percentage to its reference level are located on the level (category) within the main effect.

${ }^{\S}$ Percentages should be interpreted with caution because the relative standard error is $>30 \%$.

"Count and unadjusted percentage are not shown because there are $<30$. 
Table 2. Adjusted Associations Between Prostate-Specific Antigen Screening and Sociodemographic and ScreeningRelated Factors Among Men Aged 70 Years or Older, National Health Interview Survey 2010

\begin{tabular}{|c|c|c|c|}
\hline & Percentage* & 95\% Confidence Interval & $P^{\dagger}$ \\
\hline Total & 44.0 & $40.2-47.8$ & \\
\hline Age, years & & & .086 \\
\hline $70-74$ & 47.3 & $41.0-53.7$ & Reference \\
\hline $75-79$ & 45.5 & $38.8-52.4$ & .705 \\
\hline$\geq 80$ & 37.9 & $32.1-44.1$ & .036 \\
\hline Race/ethnicity & & & .052 \\
\hline Non-Hispanic white & 45.6 & $41.3-49.9$ & Reference \\
\hline Non-Hispanic black & 36.3 & $26.8-47.0$ & .910 \\
\hline Non-Hispanic other & 31.5 & $20.2-45.6$ & .562 \\
\hline Hispanic & 37.1 & $27.7-47.6$ & .098 \\
\hline Education & & & .131 \\
\hline Less than high school & 38.8 & $31.5-46.7$ & Reference \\
\hline High school graduate & 41.1 & $35.1-47.5$ & .650 \\
\hline Some college & 44.8 & $37.6-52.3$ & .255 \\
\hline College graduate & 51.1 & $42.9-59.2$ & .030 \\
\hline Marital status & & & .001 \\
\hline Married or living with partner & 47.4 & $42.9-51.9$ & Reference \\
\hline Widowed, divorced, or separated & 34.7 & $29.0-40.8$ & $<.001$ \\
\hline Never married & 36.5 & $22.9-52.7$ & .177 \\
\hline Usual source of medical care ${ }^{\ddagger}$ & & & .062 \\
\hline Yes & 44.4 & $40.6-48.3$ & Reference \\
\hline No & 22.6 & $9.1-46.1$ & .025 \\
\hline Family history of prostate cancer & & & .243 \\
\hline Yes & 49.8 & $39.5-60.0$ & Reference \\
\hline No & 43.3 & $39.3-47.3$ & .245 \\
\hline Comorbidity & & & .167 \\
\hline None & 38.9 & $32.0-46.4$ & Reference \\
\hline 1 disease & 46.8 & $41.3-52.5$ & .069 \\
\hline 2 diseases & 41.1 & $34.0-48.6$ & .679 \\
\hline$\geq 3$ diseases & 47.9 & $39.9-55.9$ & .095 \\
\hline Had any cancers excluding prostate cancer? & & & .284 \\
\hline Yes & 47.8 & $39.6-56.1$ & Reference \\
\hline No & 42.9 & $38.8-47.1$ & .285 \\
\hline Discussed scientific uncertainties & & & .102 \\
\hline Yes & 51.8 & $40.9-62.6$ & Reference \\
\hline No & 42.3 & $38.4-46.3$ & .106 \\
\hline Discussed advantages/disadvantages & & & $<.001$ \\
\hline None & 34.3 & $29.2-39.9$ & Reference \\
\hline Advantages only & 57.4 & $48.9-65.4$ & $<.001$ \\
\hline Disadvantages only ${ }^{\ddagger}$ & 24.1 & $5.0-65.5$ & .545 \\
\hline Both & 55.9 & $46.9-64.6$ & $<.001$ \\
\hline
\end{tabular}

* Percentages of the population estimates were adjusted for the National Health Interview Survey sampling design.

${ }^{\dagger}$ Wald $\chi^{2}$ test when the $P$ value is located on a row of a main effect. $P$ values for a general linear contrast comparing a row's percentage to its reference level are located on the level (category) within the main effect using $t$ test statistics.

${ }^{\ddagger}$ Percentages should be interpreted with caution because the relative standard error is $>30 \%$.

aligned financial incentives for physician practices might partially account for encouraging PSA testing; physicians with a laboratory on site are more likely to order a PSA test. ${ }^{24}$ Similarly, higher levels of PSA testing have been observed in Veterans Affairs hospitals with primary care incentives compared with institutions without incentives. ${ }^{25}$ Thus, the nature, context, and extent of physician-patient 
discussions of advantages and disadvantages of PSA screening must be studied further. In addition, our study revealed that a discussion about scientific uncertainties had no influence on PSA testing and that educational attainment and marital status were associated with a higher prevalence of PSA testing, as seen in other studies. ${ }^{11,13,22}$ Therefore, it is important to assess knowledge of and perspectives on prostate cancer screening among patients and their family members and educate them on how to make decisions consistent with their values and clinical needs.

Our study is subject to several limitations. First, the NHIS data were self-reported and are thus subject to recall bias. Self-reported screening behaviors may have been overestimated as a result of social desirability. ${ }^{26,27}$ Second, responses to SDM questions were structured as yes/no, lacking detailed information to understand what was discussed and whether the discussions were appropriate. Third, we were not able to assess men's knowledge, values, and preferences on prostate cancer screening to provide a more complete picture of SDM because this information was not collected by the survey. Last, given that the response rates ranged from $60 \%$ to $70 \%$, our population-based estimates might be suboptimal. However, the calculations of weights, which were adjusted for differences in probability of selection and nonresponse, might have partially corrected the bias.

\section{Conclusions}

Our study suggests that the 2008 USPSTF recommendation had little effect on prostate cancer screening. A large number of older men have continued to undergo PSA testing, and more than 70\% of these men reported not having discussions with their physician about advantages and disadvantages. Given the 2012 USPSTF recommendations that routine screening should not be performed in any age group of men, discussions between providers and men about the harms and benefits of prostate cancer screening is even more important. Discussions of advantages only and of both advantages and disadvantages of PSA testing seem to increase the uptake of prostate cancer screening. However, discussions of scientific uncertainties had no effect on PSA screening. Additional research is warranted to better understand the nature, context, and extent of physician-patient discussions and patients' knowledge of, values, and preferences for prostate cancer screening. This will be critical to help men make decisions that are most consistent with their values and preferences.

\section{References}

1. Stephenson RA. Prostate cancer trends in the era of prostate-specific antigen: an update of incidence, mortality, and clinical factors from the SEER database. Urol Clin North Am 2002;29:173-81.

2. Welch HG, Albertsen PC. Prostate cancer diagnosis and treatment after the introduction of prostatespecific antigen screening: 1986-2005. J Natl Cancer Inst 2009;101:1325-9.

3. Andriole GL, Crawford ED, Grubb RL 3rd, et al. Mortality results from a randomized prostate-cancer screening trial. N Engl J Med 2009;360:1310-9.

4. Schröder FH, Hugosson J, Roobol, MJ, et al. Screening and prostate-cancer mortality in a randomized European study. N Engl J Med 2009;360: 1320-8.

5. U.S. Preventive Services Task Force. Screening for prostate cancer: U.S. Preventive Services Task Force recommendation statement. Ann Intern Med. 2008; 149:185-91.

6. Moyer VA, U.S. Preventive Services Task Force. Screening for prostate cancer: U.S. Preventive Services Task Force Recommendation Statement. Ann Intern Med 2012;157:120-34.

7. Greene KL, Albertsen PC, Babaian RJ, et al. Prostate specific antigen best practice statement: 2009 update. J Urol 2009;182:2232-41.

8. Wolf AM, Wender RC, Etzioni RB, et al. American Cancer Society guideline for the early detection of prostate cancer: update 2010. CA Cancer J Clin. 2010;60:70-98.

9. Hoffman KE, Nguyen PL, Ng AK, D'Amico AV. Prostate cancer screening in men 75 years old or older: an assessment of self-reported health status and life expectancy. J Urol 2010;183:1798-802.

10. Drazer MW, Huo D, Schonberg MA, Razmaria A, Eggener SE. Population-based patterns and predictors of prostate-specific antigen screening among older men in the United States. J Clin Oncol 2011; 29:1736-43.

11. Li J, Zhao G, Pollack LA, Smith JL, Joseph DA. Use of the prostate-specific antigen test among men aged 75 years or older in the United States: 2006 Behavioral Risk Factor Surveillance System. Prev Chronic Dis 2010;7:A84.

12. Lu-Yao G, Stukel TA, Yao SL. Prostate-specific antigen screening in elderly men. J Natl Cancer Inst 2003;95:1792-7.

13. Ross LE, Berkowitz Z, Ekwueme DU. Use of the prostate-specific antigen test among U.S. men: findings from the 2005 National Health Interview Sur- 
vey. Cancer Epidemiol Biomarkers Prev 2008;17: 636-44.

14. Hall IJ, Taylor YJ, Ross LE, Richardsom LC, Richards TB, Rim SH. Discussions about prostate cancer screening between U.S. primary care physicians and their patients. J Gen Intern Med 2011;26:1098-104.

15. Han PK, Coates RJ, Uhler RJ, Breen N. Decision making in prostate-specific antigen screening $\mathrm{Na}$ tional Health Interview Survey, 2000. Am J Prev Med 2006;30:394-404.

16. Hoffman RM, Couper MP, Zikmund-Fisher BJ, et al. Prostate cancer screening decisions: results from the $\mathrm{Na}$ tional Survey of Medical Decisions (DECISIONS study). Arch Intern Med 2009;169:1611-8.

17. National Center for Health Statistics. National Health Interview Survey. Public use data release NHIS survey description. Hyattsville (MD): Centers for Disease Control and Prevention; 2010: 1-112.

18. Graubard BI, Korn EL. Predictive margins with survey data. Biometrics 1999;55:652-9.

19. Bellizzi KM, Breslau ES, Burness A, Waldron W. Prevalence of cancer screening in older, racially diverse adults: still screening after all these years. Arch Intern Med 2011;171:2031-7.

20. McDavid K, Melnik TA, Derderian H. Prostate cancer screening trends of New York State men at least 50 years of age, 1994 to 1997. Prev Med 2000;31: 195-202.
21. Steele CB, Miller DS, Maylahn C, Uhler RJ, Baker CT. Knowledge, attitudes, and screening practices among older men regarding prostate cancer. Am J Public Health 2000;90:1595-600.

22. Ross LE, Richardson LC, Berkowitz Z. The effect of physician-patient discussions on the likelihood of prostate-specific antigen testing. J Natl Med Assoc 2006;98:1823-9.

23. Tannor BB, Ross L. Physician-patient discussions about prostate-specific antigen test use among African-American men. J Natl Med Assoc 2006;98: 532-8.

24. Scales CD Jr, Curtis LH, Norris RD, Schulman KA, Albala DM, Moul JW. Prostate specific antigen testing in men older than 75 years in the United States. J Urol 2006;176:511-4.

25. Black A, Berg CD. Prostate-specific antigen screening for prostate cancer in older men in the United States of America. Gerontology 2012;58:331-6.

26. Bellizzi KM, Rowland JH, Jeffery DD, McNeel T. Health behaviors of cancer survivors: examining opportunities for cancer control intervention. J Clin Oncol 2005;23:8884-93.

27. Sirovich BE, Schwartz, LM, Woloshin S. Screening men for prostate and colorectal cancer in the United States: does practice reflect the evidence? JAMA 2003;289:1414-20. 